\title{
OH-defects in multiple-doped orthoenstatite at 4-8 GPa: filling the gap between pure and natural systems
}

\author{
Roland Stalder $^{1} \cdot$ Asiya Karimova $^{1} \cdot$ Jürgen Konzett $^{1}$
}

Received: 16 December 2014 / Accepted: 24 March 2015 / Published online: 4 April 2015

(C) The Author(s) 2015. This article is published with open access at Springerlink.com

\begin{abstract}
OH}$-defects in orthoenstatite were studied experimentally between 4 and $8 \mathrm{GPa}$ at $1150^{\circ} \mathrm{C}$ in the system $\mathrm{CaO}-$ $\mathrm{MgO}-\mathrm{Al}_{2} \mathrm{O}_{3}-\mathrm{SiO}_{2}-\mathrm{Cr}_{2} \mathrm{O}_{3}-\mathrm{Na}_{2} \mathrm{O}$, leading to phase assemblages enstatite \pm forsterite \pm diopside \pm garnet. In enstatite coexisting with garnet, total $\mathrm{OH}$ is negatively correlated with pressure. Conversely, in Al-poor systems without garnet, total $\mathrm{OH}$ is positively correlated with pressure, and both trends intersect around $8 \mathrm{GPa}$ and $\sim 1000$ wt ppm $\mathrm{H}_{2} \mathrm{O}$. IR-spectra of enstatite reveal several pressure sensitive features, such as (1) the absorbance of the absorption band at $3687 \mathrm{~cm}^{-1}$, (2) the band position near $3400 \mathrm{~cm}^{-1}$ and (3) the ratio $\left(A_{3240-3570} / A_{3240-3730}\right)$ and their application as geobarometer in natural samples are evaluated. For garnet-bearing phase assemblages, the band ratio $\left(A_{3240-3570} / A_{3240-3730}\right)$ in orthoenstatite defines a pressure trend in between that observed in the pure system $\mathrm{MgO}-\mathrm{SiO}_{2}-\mathrm{H}_{2} \mathrm{O}$ and that found in orthopyroxenes from natural mantle peridotites, suggesting that the application of IR-spectra as proxy for pressure is justified.
\end{abstract}

Keywords Enstatite - Geobarometer - High pressure . Water incorporation $\cdot \mathrm{OH}$-defects

\section{Introduction}

Hydrous defects make nominally anhydrous minerals (NAMs) important hosts for water in the Earth's mantle and affect their physical properties such as rheology (Mackwell

Communicated by Timothy L. Grove.

Roland Stalder

roland.stalder@uibk.ac.at

1 Institut für Mineralogie und Petrographie, Universität Innsbruck, Innrain 52 f, 6020 Innsbruck, Austria et al. 1985; Hirth and Kohlstedt 1996; Mei and Kohlstedt 2000) and electrical conductivity (Karato 1990; Wang et al. 2006; Schlechter et al. 2012). Although the nature of $\mathrm{OH}-$ defects is a complex function of many fundamental petrological parameters such as pressure, temperature, silica activity, oxygen fugacity (e.g. Withers and Hirschmann 2008), water activity and phase assemblage, certain features of the OH-defect incorporation may be used to decipher the physical conditions of NAM-formation/equilibration. Hydrous defect formation in chemically pure systems has been studied extensively during the past decades and is comparably well understood, but often not directly applicable to nature due to the absence of components that are critical for defect formation. In contrast, defect formation in natural systems is not as well understood as a result of the chemical complexity of these systems.

Here, we present results from an experimental study at 4-8 $\mathrm{GPa}$ in the system $\mathrm{CaO}-\mathrm{MgO}-\mathrm{Al}_{2} \mathrm{O}_{3}-\mathrm{SiO}_{2}-\mathrm{Cr}_{2} \mathrm{O}_{3}-$ $\mathrm{Na}_{2} \mathrm{O}$, which is intermediate in its complexity between the strongly simplified systems such as $\mathrm{MgO}-\mathrm{SiO}_{2}-\mathrm{H}_{2} \mathrm{O}$ and the natural peridotitic systems. In this system, orthoenstatite \pm diopside \pm forsterite \pm garnet coexist, reproducing the assemblage typically stable in peridotitic upper mantle at depths $<\sim 250 \mathrm{~km}$. The major aim of this study is to investigate the OH-defect inventory of orthopyroxene as major host of $\mathrm{OH}$-defects in upper mantle minerals as a function of pressure and bulk composition. Orthopyroxene has a high modal proportion in average peridotites of the uppermost mantle (olivine $>$ orthopyroxene $>$ clinopyroxene > Al-phase; Maaløe and Aoki 1977; Frey and Prinz 1978; Oehm et al. 1983) and high OH-contents

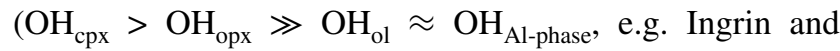
Skogby 2000; Peslier et al. 2002; Peslier and Luhr 2006; Grant et al. 2007). Thus, in the majority of mantle peridotites up to $\sim 200 \mathrm{~km}$ depth, orthopyroxene is the most 
Table 1 Run conditions, anhydrous starting mixtures and phase assemblages

\begin{tabular}{lllllllll}
\hline Run & Pressure $(\mathrm{GPa})$ & $\mathrm{SiO}_{2}$ & $\mathrm{MgO}$ & $\mathrm{CaO}$ & $\mathrm{Al}_{2} \mathrm{O}_{3}$ & $\mathrm{Cr}_{2} \mathrm{O}_{3}$ & $\mathrm{Na}_{2} \mathrm{O}$ & Phase assemblage \\
\hline AK036 & 6 & 49.45 & 43.38 & 4.75 & 1.68 & 0.39 & 0.33 & En + Di \\
AK037 & 6 & 49.45 & 43.38 & 4.75 & 1.68 & 0.39 & 0.33 & En + Di \\
AK038 & 8 & 49.45 & 43.38 & 4.75 & 1.68 & 0.39 & 0.33 & En + Di \\
AK040 & 4 & 49.56 & 41.92 & 6.25 & 1.59 & 0.36 & 0.31 & En + Di \\
AK043 & 8 & 49.34 & 44.33 & 3.75 & 1.80 & 0.42 & 0.35 & En + Di \\
AK044 & 4 & 49.34 & 44.33 & 3.75 & 1.80 & 0.42 & 0.35 & En \\
AK052 & 4 & 44.15 & 47.96 & 2.36 & 5.28 & 0.19 & 0.07 & En + Fo \\
AK056 & 8 & 43.31 & 45.17 & 2.18 & 7.14 & 0.56 & 1.63 & En + Fo $+\mathrm{Gt}$ \\
AK057 & 6 & 43.31 & 45.17 & 2.18 & 7.14 & 0.56 & 1.63 & En $+\mathrm{Fo}+\mathrm{Gt}$ \\
AK059 & 8 & 44.58 & 49.71 & 2.40 & 2.03 & 0.30 & 0.97 & En $+\mathrm{Fo}+\mathrm{Gt}$ \\
AK060 & 4 & 43.33 & 45.16 & 2.18 & 7.14 & 0.56 & 1.63 & En $+\mathrm{Fo}+\mathrm{Gt}^{\mathrm{a}}$ \\
AK064 & 4 & 40.56 & 42.41 & 2.82 & 12.11 & 1.06 & 1.03 & En $+\mathrm{Fo}+\mathrm{Gt}^{\mathrm{a}}$ \\
\hline
\end{tabular}

En enstatite, $D i$ diopside, Fo forsterite, $G t$ garnet

${ }^{\text {a }}$ Gt was not observed, but inferred from bulk and crystal chemistry considerations. All experimental charges contained a solid-water mixture in an approximate weight ratio of 85:15 important $\mathrm{OH}$-carrier, if nominally hydrous phases are not present.

In this study, OH-defects are characterised and quantified by FTIR spectroscopy. OH-dipoles revealed by IR absorptions are produced by point defects, where protons act as charge compensation for metal vacancies or impurities. Since oxygen is the only charge balancing anion in the crystal, the relevant component for petrology and geochemistry is water. Therefore, throughout this article, the terms "OH-incorporation", "hydrogen incorporation", "proton incorporation" and "water incorporation" are used synonymously. Concentrations are given as wt ppm water.

\section{Experimental procedure}

For the starting materials, high-purity oxides and carbonates were mixed in appropriate stoichiometric proportions (Table 1) and these mixtures were decarbonated by stepwise firing to $1000{ }^{\circ} \mathrm{C}$. Approximately $20 \mathrm{mg}$ solid starting material was then loaded into a platinum capsule with an outer (inner) diameter of 3.0 (2.6) $\mathrm{mm}$, respectively. Prior to sealing water was added with a micro-syringe in order to yield a silicate-to-water ratio of 85:15.

High-pressure/high-temperature experiments were performed with a 1000-ton Walker-type multianvil device at the University of Innsbruck using 25/15 assemblies with $\mathrm{MgO}-\mathrm{Cr}_{2} \mathrm{O}_{3}$ octahedra and graphite furnaces. Experimental and calibration conditions are similar to those described by Rubie et al. (1993) and Keppler and Frost (2005), and the pressure is estimated to be correct within $0.2 \mathrm{GPa}$. Temperature was measured with a $\mathrm{Pt}_{100}-\mathrm{Pt}_{90} \mathrm{Rh}_{10}$ thermocouple, and both pressure and temperature were computer-controlled during the entire duration of the runs. For each run, the temperature was initially raised to $1300{ }^{\circ} \mathrm{C}$ and held for $3 \mathrm{~h}$ followed by a decrease to $1150{ }^{\circ} \mathrm{C}$ at a rate of $10^{\circ} \mathrm{C} / \mathrm{h}$. As soon as the final temperature was reached, runs were terminated by shutting off the heating power. After removal from the assembly, the capsules were weighed, pierced, dried and weighed again to determine the amount of fluid present during the experiment and to check for any fluid loss. This test showed that with the exception of run AK38 (Table 1), no significant fluid loss had occurred. Run AK38 still produced large and euhedral orthopyroxene grains which was taken as indication for the presence of fluid during the experiments.

Run products were inspected under an optical microscope and analysed without further preparation or grinding by X-ray diffraction using a Bruker-AXS D8 powder diffractometer equipped with an energy dispersive SOL-X detector in parallel beam optics mode, or a Siemens D5000 powder diffractometer with a scintillation counter in Bragg-Brentano geometry in the $2 \theta$ range between $2^{\circ}$ and $70^{\circ}\left(\mathrm{Cu}-\mathrm{K}_{\alpha}\right.$ radiation, generator settings: $40 \mathrm{kV} / 40 \mathrm{~mA}$, step size: $0.01^{\circ} 2 \theta$ ). Single crystals of enstatite were handpicked under a binocular microscope and oriented in a thermoplastic resin parallel (010) and (100). The proper alignment was checked using a polarisation microscope with conoscopic illumination and a posteriori verified by IRspectroscopy based on the lattice overtones (see analytical section). All crystal sections were polished on both sides, reaching a final thickness of 50-300 $\mu \mathrm{m}$. After preparation, the thermoplastic resin was removed by rinsing in acetone. Crystals of accompanying phases generally were too small to get aligned and analysed by FTIR, because the study was focussed on $\mathrm{OH}$-defects in enstatite, and therefore, the bulk composition was adjusted to produce a large proportion (and hence large crystals) of enstatite. 
Table 2 Chemical compositions (wt \%) of crystalline phases determined by electron microprobe (analytical error in parentheses)

\begin{tabular}{|c|c|c|c|c|c|c|c|c|c|c|}
\hline Phase & Run & analyses & $\mathrm{SiO}_{2}$ & $\mathrm{MgO}$ & $\mathrm{CaO}$ & $\mathrm{A}_{2} \mathrm{O}_{3}$ & $\mathrm{Cr}_{2} \mathrm{O}_{3}$ & $\mathrm{Na}_{2} \mathrm{O}$ & Mole $\mathrm{Al} /(\mathrm{Al}+\mathrm{Cr})$ & Total wt $\%$ \\
\hline En & AK036 & 17 & $59.77(0.24)$ & $38.18(0.17)$ & $0.83(0.12)$ & $0.33(0.06)$ & $0.29(0.05)$ & $0.04(0.01)$ & 0.63 & 99.43 \\
\hline En & AK037 & 22 & $59.72(0.26)$ & $38.18(0.23)$ & $0.97(0.13)$ & $0.29(0.10)$ & $0.26(0.05)$ & $0.03(0.01)$ & 0.62 & 99.45 \\
\hline En & AK038 & 4 & $59.82(0.23)$ & $38.21(0.28)$ & $0.91(0.03)$ & $0.39(0.02)$ & $0.25(0.06)$ & $0.02(0.01)$ & 0.70 & 99.59 \\
\hline En & AK040 & 13 & $59.72(0.18)$ & $38.18(0.25)$ & $0.92(0.18)$ & $0.15(0.04)$ & $0.34(0.12)$ & $0.02(0.01)$ & 0.40 & 99.32 \\
\hline En & AK043 & 15 & $59.35(0.25)$ & $40.22(0.17)$ & $0.77(0.08)$ & $0.40(0.09)$ & $0.26(0.08)$ & $0.03(0.02)$ & 0.70 & 101.04 \\
\hline En & AK044 & 16 & $59.77(0.34)$ & $40.59(0.27)$ & $0.32(0.04)$ & $0.14(0.05)$ & $0.26(0.09)$ & $0.01(0.01)$ & 0.45 & 101.08 \\
\hline En & AK052 & 9 & $59.00(0.43)$ & $40.70(0.04)$ & $0.28(0.04)$ & $0.70(0.21)$ & $0.32(0.08)$ & $0.03(0.01)$ & 0.77 & 100.79 \\
\hline En & AK056 & 16 & $58.97(0.28)$ & $40.69(0.27)$ & $0.36(0.11)$ & $0.50(0.11)$ & $0.16(0.07)$ & $0.11(0.03)$ & 0.82 & 100.80 \\
\hline En & AK057 & 5 & $58.78(0.36)$ & $39.95(0.50)$ & $0.34(0.01)$ & $0.79(0.07)$ & $0.21(0.03)$ & $0.06(0.01)$ & 0.85 & 100.12 \\
\hline En & AK059 & 5 & $58.83(0.25)$ & $39.78(0.39)$ & $0.25(0.02)$ & $0.43(0.05)$ & $0.25(0.01)$ & $0.07(0.01)$ & 0.72 & 99.60 \\
\hline En & AK060 & 10 & $57.45(0.47)$ & $38.63(0.41)$ & $0.23(0.01)$ & $2.21(0.41)$ & $1.35(0.21)$ & $0.07(0.02)$ & 0.71 & 99.95 \\
\hline En & AK064 & 7 & $55.94(0.38)$ & $38.18(0.43)$ & $0.20(0.01)$ & $4.46(0.39)$ & $1.02(0.16)$ & $0.04(0.02)$ & 0.87 & 99.86 \\
\hline Di & AK036 & 2 & $59.79(0.52)$ & $18.45(0.42)$ & $20.63(0.17)$ & $3.92(0.59)$ & $0.37(0.02)$ & $0.72(0.11)$ & 0.94 & 99.87 \\
\hline Di & AK038 & 6 & $56.56(0.20)$ & $21.22(0.36)$ & $21.45(0.41)$ & $0.56(0.04)$ & $0.50(0.04)$ & $0.28(0.05)$ & 0.62 & 100.58 \\
\hline Di & AK040 & 2 & $55.82(0.62)$ & $22.12(0.21)$ & $20.27(0.61)$ & $1.55(0.13)$ & $0.23(0.08)$ & $0.12(0.02)$ & 0.91 & 100.10 \\
\hline Di & AK043 & 15 & $55.59(0.33)$ & $21.23(0.32)$ & $22.11(0.29)$ & $0.66(0.08)$ & $0.60(0.14)$ & $0.36(0.05)$ & 0.62 & 100.55 \\
\hline Gt & AK057 & 3 & $43.18(0.77)$ & $26.53(0.32)$ & $5.83(0.23)$ & $23.33(0.18)$ & $1.15(0.19)$ & $0.03(0.02)$ & 0.97 & 100.05 \\
\hline
\end{tabular}

En enstatite, $D i$ diopside, Gt garnet

\section{Analytical procedure}

\section{Electron microprobe}

To determine the composition of the run products, handpicked crystals of sufficient size were embedded in epoxy resin and analysed with a JEOL JXA-8100 electron microprobe in the wavelength-dispersive analytical mode. Analytical conditions were $15 \mathrm{kV}$ acceleration voltage and $10 \mathrm{nA}$ beam current with measurement durations of 20 and $10 \mathrm{~s}$ on peaks and background, respectively, for each $\mathrm{X}$-ray line. The following standards were used: synthetic quartz $(\mathrm{Si})$, synthetic corundum $(\mathrm{Al})$, natural diopside $(\mathrm{Mg}, \mathrm{Ca})$, jadeite $(\mathrm{Na})$ and chromite $(\mathrm{Cr})$. Detection limits were around $100 \mathrm{ppm}(\mathrm{wt})$ for $\mathrm{Si}, \mathrm{Al}$ and $\mathrm{Ca}, 130 \mathrm{ppm}$ (wt) for $\mathrm{Mg}$ and $\mathrm{Na}$ and $200 \mathrm{ppm}$ for $\mathrm{Cr}$. Inspection using BSE imaging and analyses of traverses across individual orthopyroxene crystals revealed no significant compositional zoning. Analytical results are given in Table 2.

\section{FTIR spectroscopy and trace water quantification}

Mid-infrared absorption spectra were recorded at room temperature in transmission mode using a Bruker Vertex 70 FTIR spectrometer, coupled to a Hyperion 3000 microscope equipped with liquid nitrogen-cooled MCT-D316025 (mercury cadmium telluride) detector, a silicon carbide (SiC) global source, a $\mathrm{KBr}$ beam splitter and a $\mathrm{ZnSe}$ wire grid polarizer. Each spectrum was acquired by 32 scans in the range between 550 and $7500 \mathrm{~cm}^{-1}$ with a spectral resolution of $2 \mathrm{~cm}^{-1}$. Spectra were recorded over a large portion of each crystal as average values, representing a volume comparable to that analysed by electron microprobe. As the chemical zonation with respect to metal impurities was rather small, no attempt to quantify the zonation in $\mathrm{OH}-$ content was made. Special attention was drawn to the spectral region of $\mathrm{OH}$-stretching vibrations $\left(3000-3700 \mathrm{~cm}^{-1}\right)$ and the lattice overtones $\left(1200-2200 \mathrm{~cm}^{-1}\right)$, the latter being used to confirm the polarisation direction by comparison with previously published spectra (Prechtel and Stalder 2012; Mosenfelder and Rossman 2013) and to independently check the thickness of the crystal section by the intensity of the overtones. $\mathrm{OH}$-defect contents, expressed as wt ppm water, were calculated using the calibrations of Bell et al. (1995), Libowitzky and Rossman (1997) and Stalder et al. (2012). Results are summarised in Table 3.

\section{Results}

\section{Run products}

All runs produced orthoenstatite with crystals up to several $100 \mu \mathrm{m}$ in size, free fluid and amorphous quench material. Depending upon the composition of the starting material and the pressure, diopside, forsterite and/or garnet appeared in addition (Table 1). In some runs with high $\mathrm{Al}$ bulk compositions (e.g. AK52, AK60, AK64), X-ray diffraction analysis indicated the presence of sheet silicates with $12 \AA$ spacing. These sheet silicates, however, could not be detected 
Table 3 IR integral absorbances $(n \alpha+n \beta+n \gamma)$ normalised to $1 \mathrm{~mm}$ thickness and calculated water contents

\begin{tabular}{|c|c|c|c|c|c|c|c|c|}
\hline \multirow[t]{2}{*}{ Run } & \multirow[t]{2}{*}{ Pressure (GPa) } & \multirow[t]{2}{*}{$A_{3570-3730}\left(\mathrm{~cm}^{-2}\right)$} & \multirow[t]{2}{*}{$A_{3240-3570}\left(\mathrm{~cm}^{-2}\right)$} & \multirow[t]{2}{*}{$A_{3240-3730}\left(\mathrm{~cm}^{-2}\right)$} & \multirow[t]{2}{*}{$\frac{A_{3240-3570}}{A_{3240-3730}}$} & \multicolumn{3}{|c|}{ wt ppm $\mathrm{H}_{2} \mathrm{O}$} \\
\hline & & & & & & LR97 & B95 & St12 \\
\hline AK036 & 6 & 20.0 & 351.6 & 371.6 & 0.946 & 712 & 845 & 1122 \\
\hline AK037 & 6 & 27.2 & 260.6 & 287.8 & 0.906 & 590 & 646 & 952 \\
\hline AK038 & 8 & 36.0 & 366.3 & 402.3 & 0.911 & 761 & 810 & 1232 \\
\hline AK040 & 4 & 13.7 & 236.7 & 250.4 & 0.945 & 484 & 576 & 761 \\
\hline AK043 & 8 & 67.7 & 775.5 & 843.2 & 0.920 & 1591 & 1736 & 2543 \\
\hline AK044 & 4 & 20.4 & 253.5 & 273.9 & 0.926 & 550 & 629 & 881 \\
\hline AK052 & 4 & 50.2 & 350.0 & 400.2 & 0.875 & 814 & 831 & 1319 \\
\hline AK056 & 8 & 90.6 & 398.9 & 489.5 & 0.815 & 1132 & 1067 & 1935 \\
\hline AK057 & 6 & 105.0 & 539.1 & 644.1 & 0.837 & 1380 & 1286 & 2289 \\
\hline AK059 & 8 & 100.5 & 418.3 & 518.8 & 0.806 & 1204 & 1073 & 2077 \\
\hline $\mathrm{AK} 060^{\mathrm{a}}$ & 4 & (68.8) & (430.7) & (499.5) & $(0.862)$ & 1523 & 1456 & 2460 \\
\hline AK064 & 4 & 128.8 & 682.4 & 811.2 & 0.841 & 1586 & 1524 & 2554 \\
\hline
\end{tabular}

LR97 = Libowitzky and Rossman (1997), B95 = Bell et al. (1995), Stl2 = Stalder et al. (2012)

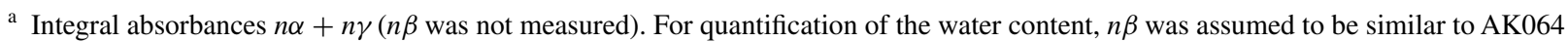

by optical inspection and, hence, are thought to be metastable quench products. As the detection of accompanying phases was difficult if their modal proportion was very low, additional information based on crystal chemistry of the observed phases was further considered. Ca-saturation of enstatite based on the diopside-enstatite solvus (Nickel and Brey 1984) was taken as indication for the presence of diopside in cases when this phase could not be detected due to its low modal proportions. This issue will be discussed in more detail in the next section. Likewise, the Al-content of enstatite served as sensitive indicator for the presence or absence of garnet (cf. Lane and Ganguly 1980). In runs where two pyroxenes coexist, a negative correlation of $\mathrm{Al} /(\mathrm{Cr}+\mathrm{Al})$ in clinopyroxene with pressure was observed (Table 2), in agreement with results obtained by Nimis and Taylor (2000).

\section{IR-spectra of orthoenstatite}

IR-spectra of orthoenstatite exhibit many absorption bands between 3000 and $3700 \mathrm{~cm}^{-1}$ (Fig. 1), some of them amalgamating to broad absorption features similar to those known from natural specimens (e.g. Bell et al. 1995; Pre-

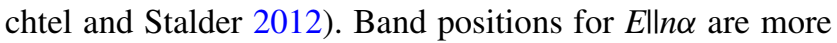
similar to $E \| l n \gamma$ than to $E \| n \beta$ (in accord with Prechtel and Stalder 2011, 2012), but considerable deviations from this behaviour are observed for samples with high Al-content. High-wavenumber bands $>3570 \mathrm{~cm}^{-1}$ are most strongly developed for $E \|_{n} \beta$, but in some samples also show significant contributions for $E \| n \alpha$. IR-spectra summed over all three polarisation directions $E\|n \alpha+E\| n \beta+E \| n \gamma$ show systematic changes dependent upon phase assemblage (Fig. 2a) and pressure (Fig. 2b, c). Specifically, high-wavenumber absorption bands such as the one at $3687 \mathrm{~cm}^{-1}$ tend to increase with pressure in comparison with low-wavenumber absorption bands, and the band near $3600 \mathrm{~cm}^{-1}$ shows a positive correlation between intensity and bulk Al-content, culminating in maximum intensities in garnet-bearing assemblages (Fig. 2a). Integral absorbances for bands $>3570 \mathrm{~cm}^{-1}$ and $<3570 \mathrm{~cm}^{-1}$ are listed in Table 3, and water concentrations determined by the calibrations of Bell et al. (1995), Libowitzky and Rossman (1997) and Stalder et al. (2012) are plotted in Fig. 3. With the calibration of Bell et al. (1995), spectra with a larger proportion of low-wavenumber bands yield systematically higher water contents than with the calibration of Libowitzky and Rossman (1997) (Fig. 3b), which is in agreement with Mosenfelder and Rossman (2013). In general, water concentrations of samples synthesised under similar $P-T-x$ conditions are in good agreement. The only exception is the discrepancy between AK38 and AK43 (En + Di at 8 GPa), which was caused by partial fluid loss from AK38.

\section{Discussion}

\section{Di-En solvus}

In charges where two pyroxenes coexist, enstatite (En) contains on average $3 \mathrm{~mol} \%$ diopside (Di) component and diopside contains between 15 and $22 \mathrm{~mol} \%$ enstatite component (Table 2; Fig. 4). The latter value is slightly higher than expected for a temperature of $1150{ }^{\circ} \mathrm{C}$ in the system $\mathrm{CaO}-\mathrm{MgO}-\mathrm{SiO}_{2}$ (Nickel and Brey 1984). This discrepancy, however, can be explained if the temperature history of the 

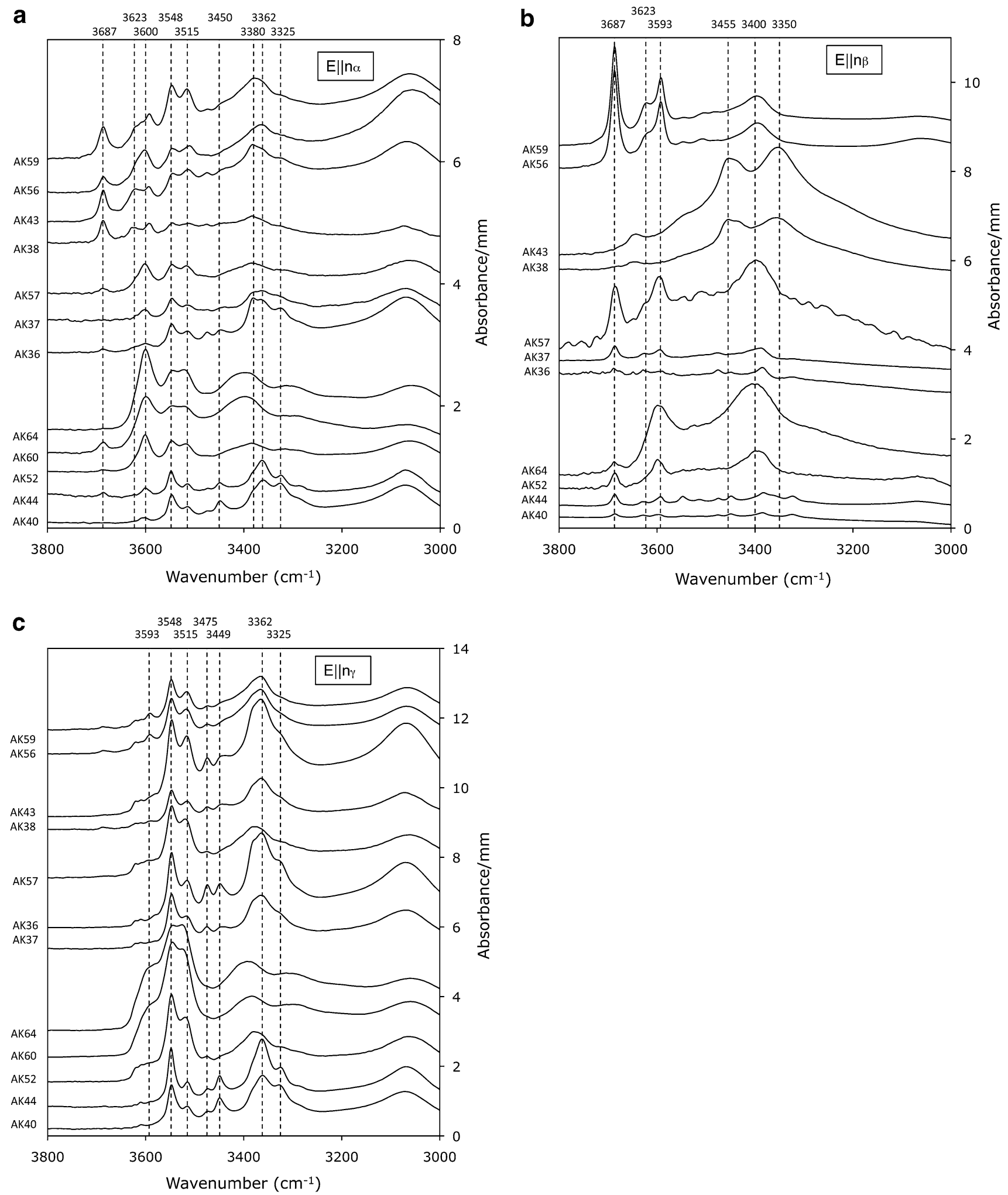

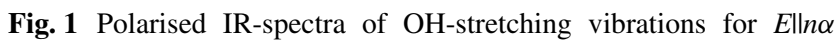
(a), $E \| n \beta$ (b) and $E \| n \gamma(\mathbf{c})$ recorded on oriented enstatite single crys-

Spectra are not baseline corrected, normalised to $1 \mathrm{~mm}$ thickness, grouped according to pressure (details see Tables 1,2) and offset for tal sections. Most prominent bands are highlighted by broken lines. 

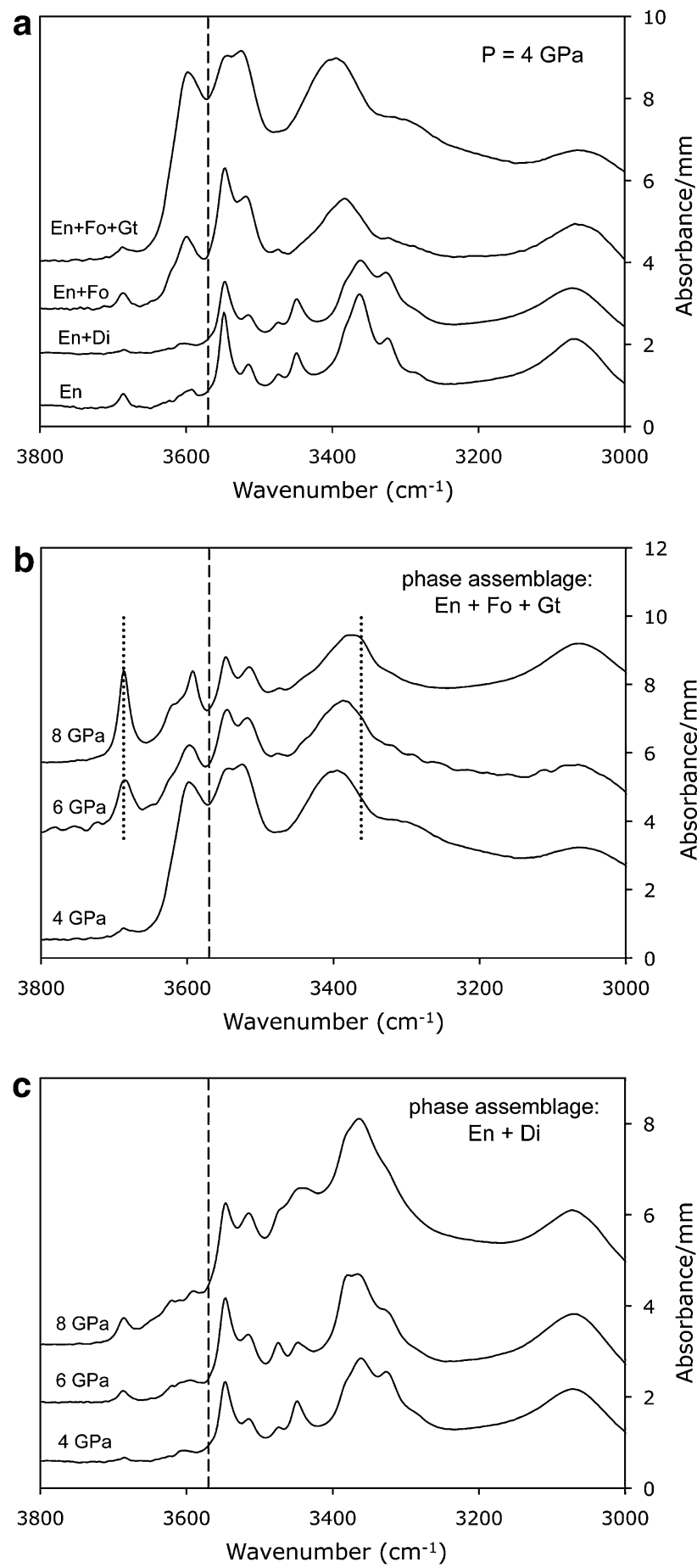

Fig. 2 IR-spectra of OH-stretching vibrations shown as $E\|n \alpha+E\| n \beta+E \| n \gamma$ from polarised measurements on oriented crystal sections. Comparison of different phase assemblages at constant pressure (a), pressure dependence of the phase assemblage $\mathrm{En}+\mathrm{Fo}+\mathrm{Gt}(\mathbf{b})$ and En + Di (c). When data from two runs with the same conditions were available (e.g. AK36/37, AK38/43 and AK56/59), average spectra are shown. Bands assigned to $\mathrm{OH}$ associated with metal vacancies in pure enstatite are shown in $\mathbf{b}$ as dotted lines. The subsequently used division between high-wavenumber and low-wavenumber bands at $3570 \mathrm{~cm}^{-1}$ is also displayed as broken line. Spectra are normalised to $1 \mathrm{~mm}$ thickness and offset for clarity
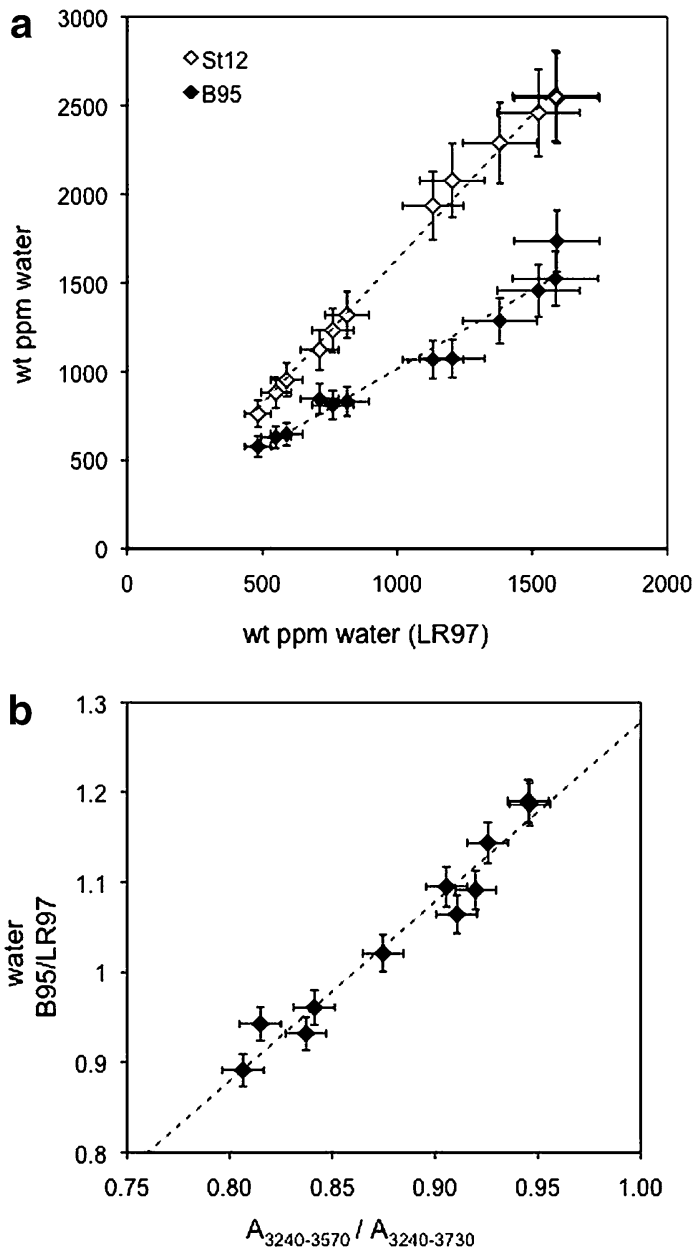

Fig. 3 Water contents of enstatite using the calibrations of Bell et al. $(1995)=$ B95 and Stalder et al. (2012) = St12 plotted against water contents using the calibration of Libowitzky and Rossman (1997) = LR97 (a). A higher proportion of low-wavenumber bands $\left(A_{3240-3570}\right)$ results in an overestimation of B95 compared to LR97 (b)

experiments is considered: the observed range in pyroxene Ca-contents is thought to be a result of continuous pyroxene crystallization over a temperature interval of $150{ }^{\circ} \mathrm{C}$ (i.e. from 1300 to $1150{ }^{\circ} \mathrm{C}$, cf. Figure 4) and reflects incomplete re-equilibration of $\mathrm{Ca}$ in orthopyroxene at the final run temperature of $1150{ }^{\circ} \mathrm{C}$. This assumption is consistent with temperatures of $1275{ }^{\circ} \mathrm{C}$ derived from two-pyroxene thermometry based on the calibration by Nimis and Taylor (2000). An excess diopside component in enstatite incorporated at an early stage of the experiments, however, is not likely to affect water incorporation into enstatite to any significant degree as will be discussed in the next paragraph.

\section{Water in enstatite}

Water concentrations show a positive correlation with pressure for the phase assemblage enstatite + diopside (Fig. 5), 


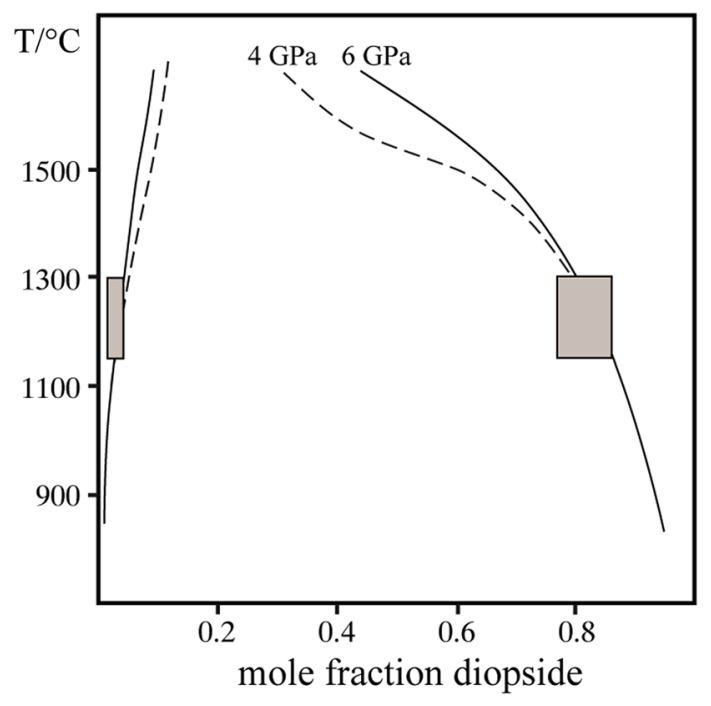

Fig. 4 Range of diopside-enstatite solid solution (grey boxes) in runs, where both pyroxenes coexist. Solvus for $4 \mathrm{GPa}$ (broken line) and 6 GPa (solid line) after Nickel and Brey (1984) for comparison

which is in good agreement with data for pure orthoenstatite obtained by Rauch and Keppler (2002). Therefore, it is concluded that the diopside component in enstatite has no significant influence on $\mathrm{OH}$-incorporation, at least at small molar fractions of diopside as in the present study $\left(\mathrm{En}_{97} \mathrm{Di}_{3}\right.$ in run $\mathrm{AK} 40$ and $\mathrm{En}_{99} \mathrm{Di}_{1}$ in $\mathrm{AK} 44$, both showing water concentration identical within the analytical error, see Table 3). The diopside component itself has generally been shown to be a poor water carrier compared to the enstatite component, because (1) pure diopside shows rather low $\mathrm{OH}-$ defect contents unless doped with monoor trivalent metal cations (Stalder and Ludwig 2007; Purwin et al. 2009), (2) in the undoped $\mathrm{CaO}-\mathrm{MgO}-\mathrm{SiO}_{2}$ system, the water partition coefficient between enstatite and diopside is $>1$, and (3) diopside in the phase assemblage $\mathrm{Di}+$ En has a higher concentration of hydrous defects than in the assemblage $\mathrm{Di}+$ Wo, where diopside is close to stoichiometry (Karimova and Stalder 2013), which means that a dissolved enstatite component in diopside has a stronger influence on $\mathrm{OH}$ in diopside than a dissolved diopside component in enstatite.

Water incorporation into enstatite also depends on the coexisting phase assemblage, but this trend is governed by the $\mathrm{Al}$-content in enstatite rather than the coexistence with an Al-rich phase. Enstatite with an Al-content just below Al-saturation incorporates similar amounts of $\mathrm{OH}$-defect contents as at Al-saturation, and the high water contents in enstatite coexisting with garnet are due to the high Alcontents in enstatite compared to Al-free (or Al-poor) systems. The observed negative correlation with pressure is opposite to the trend observed for enstatite coexisting with diopside only. Both, Al-saturated and undersaturated trends

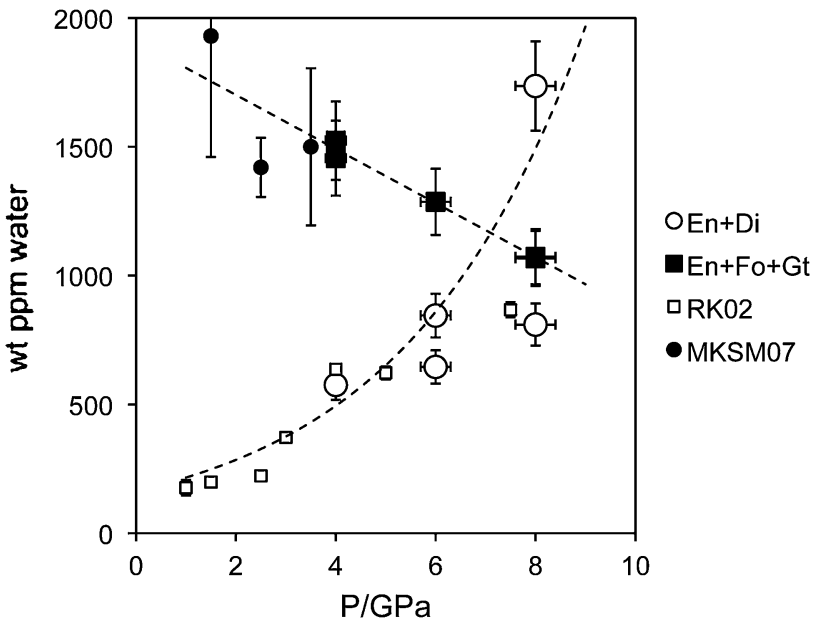

Fig. 5 Water content (as OH-defects) in enstatite against pressure using the calibration of Bell et al. (1995). RK02 and MKSM07 are data for pure and Al-saturated orthoenstatite at $1100{ }^{\circ} \mathrm{C}$ from Rauch and Keppler (2002) and Mierdel et al. (2007), respectively. The large discrepancy between the two $8 \mathrm{GPa}$ runs with $(\mathrm{En}+\mathrm{Di})$ are probably caused by partial fluid loss from AK38

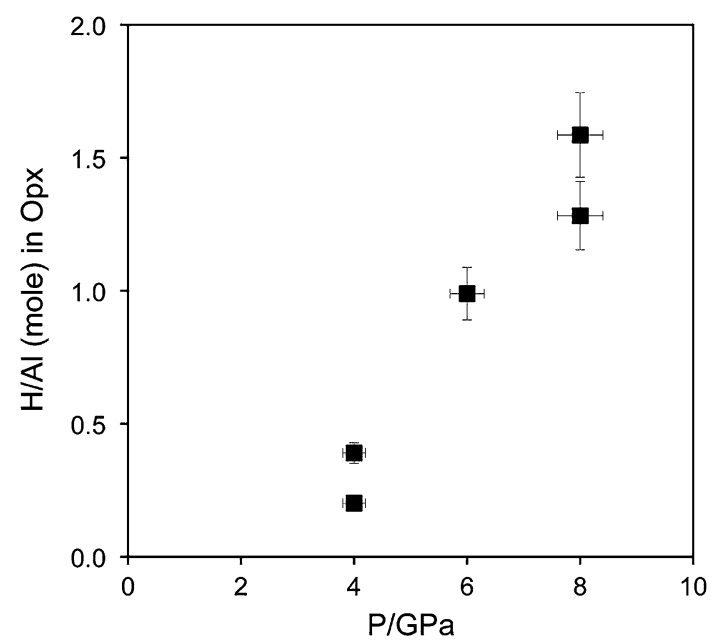

Fig. 6 Role of $\mathrm{Al}$ for incorporation of $\mathrm{H}$ in enstatite in the phase assemblage $\mathrm{En}+\mathrm{Fo}+\mathrm{Gt}$ as function of pressure. H-concentration was calculated from the water content using the calibration of Bell et al. (1995)

intersect near $8 \mathrm{GPa}$ and approximately 1000 wt ppm $\mathrm{H}_{2} \mathrm{O}$ (Fig. 5). Taken into account that Al-incorporation in enstatite is negatively correlated with pressure in the garnet stability field (Lane and Ganguly 1980), this means that the $\mathrm{H}^{+} / \mathrm{Al}^{3+}$ ratio increases with pressure (Fig. 6). This trend can, however, not be interpreted as a more effective coupling of $\mathrm{H}^{+}$to $\mathrm{Al}^{3+}$ as the increased incorporation of protons also is observed in the Al-free system (Rauch and Keppler 2002), and the reduced $\mathrm{Al}^{3+}$-content can be related to reduced Tschermaks substitution at high pressure. In 
particular, at $4 \mathrm{GPa}$, most of the $\mathrm{Al}^{3+}$ is incorporated by Tschermaks substitution and only a small fraction is coupled to $\mathrm{H}^{+}$. Therefore, it is more likely that with increasing pressure water incorporation is more and more charge compensated by metal vacancies and less strongly promoted by $\mathrm{Al}^{3+}$, in agreement with Mierdel et al. (2007). This interpretation is further strengthened by the positive correlation between pressure and the absorbance of the band at 3687 and $3362 \mathrm{~cm}^{-1}$ (Fig. 2b). The latter has been assigned to $\mathrm{Mg}^{2+}=2 \mathrm{H}^{+}$(Prechtel and Stalder 2011), but concerning the $3687 \mathrm{~cm}^{-1}$ band, a consensus in recent literature has not been reached. On the one hand, the $3687 \mathrm{~cm}^{-1}$ band correlates with the silica content of the system and exhibits polarisation properties and a pressure trend similar to the band at $3593 \mathrm{~cm}^{-1}$, which has been assigned as hydrogarnet substitution $\left(\mathrm{Si}^{4+}=4 \mathrm{H}^{+}\right)$by Prechtel and Stalder $(2010$, 2011). On the other hand, this band has been interpreted as a result of inclusions of amphibole (Skogby and Rossman 1989; Mosenfelder and Rossman 2013) that undoubtedly occur in natural samples. Since the stability of amphibole under the experimental conditions of this study can be ruled, we do not favour an interpretation of the band at $3687 \mathrm{~cm}^{-1}$ as a result of amphibole inclusions. However, other defect species such as planar defects are not excluded.

Orthopyroxenes from upper mantle peridotite xenoliths typically show water concentrations that are only approximately one-tenth of those encountered in enstatite from the water-saturated experiments of this study (Fig. 7). The most important reason is that the water activity in the upper mantle is much lower than in the high-pressure experiments. The relatively low water content in mantle pyroxenes in general, as well as the high variability in water contents amongst mantle pyroxenes, cannot be explained by the trace metal chemistry in pyroxene (formation of anhydrous defects, such as Al-Cr-Tschermaks component, by mutual compensation of different Al- and $\mathrm{Cr}$-induced $\mathrm{OH}$-defects, e.g. Prechtel and Stalder 2012), because data points for Alsaturated enstatite from this study fall on the same trend line as that obtained by Mierdel et al. (2007) in the system $\mathrm{MgO}-\mathrm{Al}_{2} \mathrm{O}_{3}-\mathrm{SiO}_{2}-\mathrm{H}_{2} \mathrm{O}$ (Fig. 5), illustrating the predominant importance of $\mathrm{Al}$ for the generation of $\mathrm{OH}$-defects in enstatite. $\mathrm{Fe}^{3+}$, another metal impurity not encountered in our experiments, is expected to behave similar to $\mathrm{Cr}^{3+}$ and promotes coupled substitution involving protons during water-saturated crystallisation (Stalder 2004), and therefore is not judged relevant in this context either. Therefore, the variability in the water content of mantle orthopyroxenes most likely is due to variations in the water activity in the respective environment, triggered by processes such as melt depletion or metasomatism (Peslier et al. 2012; Warren and Hauri 2014), or by partial hydrogen loss as a result of oxidation of ferrous to ferric iron during uplift, leading in some cases to lower water contents than representative

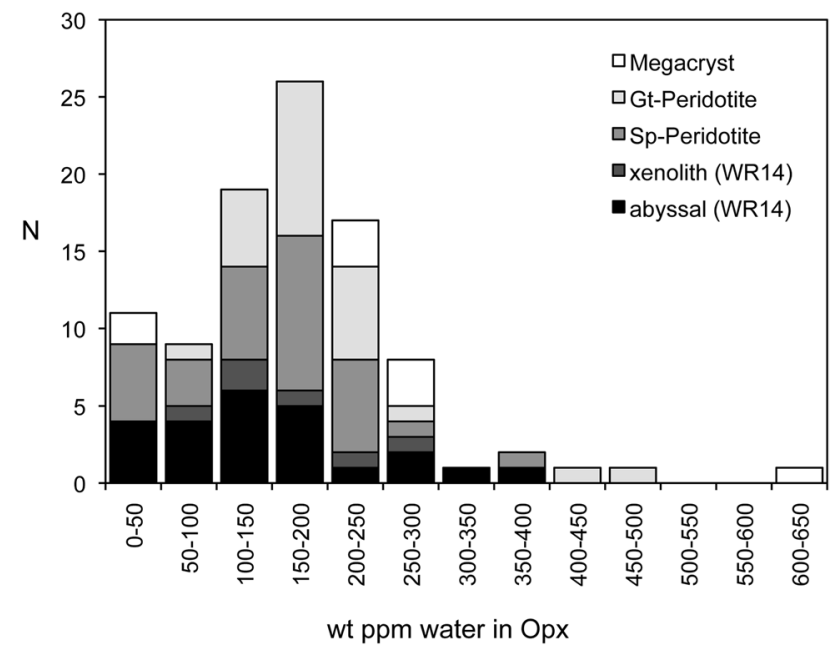

Fig. 7 Compilation of published water contents in orthopyroxene (Bell and Rossman 1992; Bell et al. 2004; Grant et al. 2007; Peslier et al. 2002; Rossman 1996; Sundvall and Stalder 2011; Peslier et al. 2012; Mosenfelder and Rossman 2013; Warren and Hauri 2014) from different lithologies in the Earth's upper mantle. Water contents for WH14 (Warren and Hauri 2014) were measured by SIMS, and all other samples were analysed by FTIR using the calibration of Bell et al. (1995)

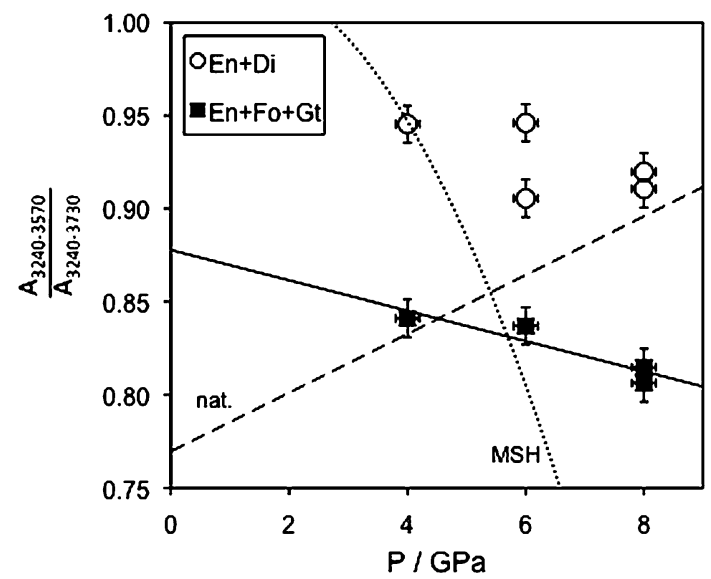

Fig. 8 Correlation between band ratio $A_{3240-3570} / A_{3240-3730}$ and pressure for enstatite in phase assemblages $\mathrm{En}+\mathrm{Di}$ and $\mathrm{En}+\mathrm{Fo}+\mathrm{Gt}$. Trends for En + Fo in the pure MSH-system (Prechtel and Stalder 2011) and for natural mantle samples (Prechtel and Stalder 2012) are shown as dotted and broken line, respectively

for upper mantle $P-T-f \mathrm{O}_{2}$ conditions (Skogby and Rossman 1989).

\section{Band ratios of $\mathrm{OH}$ absorptions in enstatite: relevance for natural systems}

One of the principal aims of this study is the identification of potentially pressure sensitive features of the IRspectra of enstatite in the spectral region of $\mathrm{OH}$-stretching 
vibrations. For an easier comparison with data from previous studies (e.g. Prechtel and Stalder 2012), a distinction between high- and low-wavenumber bands was made and the integral absorbance ratio $\left(A_{3240-3570} / A_{3240-3730}\right)$ used as proxy for pressure. Results from this study are treated as two subsets based on the phase assemblages En + Di and En + Fo + Gt, respectively. Enstatite from both phase assemblages shows a similar and weak negative correlation between absorbance ratio $\left(A_{3240-3570} / A_{3240-3730}\right)$ and pressure (Fig. 8), albeit with a shift of the trend for $\mathrm{En}+\mathrm{Di}+\mathrm{Gt}$ to significantly lower values. It has also to be noted that the observed pressure trend of $\left(A_{3240-}\right.$ ${ }_{3570} / A_{3240-3730}$ ) in natural samples (Prechtel and Stalder 2012) is mainly due to the different behaviour of the bands between 3600 and $3515 \mathrm{~cm}^{-1}$ and not due to the bands above $3600 \mathrm{~cm}^{-1}$ as in the present study (Fig. 2b).

Another pressure sensitive feature of the IR-spectra of enstatite in the assemblage En + Fo + Gt is the continuous shift of the Elln $\gamma$ component of the OH-band generated by octahedral OH-defects. This band is observed at $3362 \mathrm{~cm}^{-1}$ at low levels of bulk Al (Fig. 2a) and in systems without any impurity cations (Prechtel and Stalder 2011). In case of Alsaturation at $4 \mathrm{GPa}$, it has a maximum at $3400 \mathrm{~cm}^{-1}$, which is shifted back to $3362 \mathrm{~cm}^{-1}$ at $8 \mathrm{GPa}$ (Fig. 1c, 2b). As discussed above, this shift is probably caused by a reduced coupled incorporation of $\mathrm{Al}^{3+}$ and $\mathrm{H}^{+}$and a concomitant increased amount of $\mathrm{Mg}^{2+}=2 \mathrm{H}^{+}$exchange, making the $\mathrm{OH}-$ defects in the octahedral site more similar to the $\mathrm{OH}$-defect in the pure endmember. This pressure-dependent shift, however, is not observed in natural samples (cf. Prechtel and Stalder 2012) and therefore cannot be used as geobarometer.

If the absorption band at $3687 \mathrm{~cm}^{-1}$ in both investigated phase assemblages (Fig. 2b, c) is assigned to protonated Si-vacancies (Prechtel and Stalder 2010, 2011), its positive correlation with pressure may reflect a decreasing silica activity with increasing pressure. This phenomenon has been observed in partial melts from peridotitic systems that show decreasing silica contents with increasing pressure (Takahashi 1986). This effect is more pronounced in Alsaturated enstatite coexisting with garnet than in Al-undersaturated systems because with increasing pressure less tetrahedral $\mathrm{Al}$ is incorporated into enstatite. It should be noted that the saturation of an Al-rich phase (rather than coexistence with garnet) is the important factor, so the presence of spinel or plagioclase at lower-pressure regimes would also constrain the $\mathrm{Al}$-specific $\mathrm{OH}$-defects in enstatite.

Based on the results of the present study, it is not possible to satisfactorily explain the discrepancy in $\mathrm{H}_{2} \mathrm{O}$ contents of enstatite between the synthetic bulk systems of this study and natural systems. One general problem for natural systems is broad and overlapping absorption bands that makes the quantitative characterisation of the defect chemistry and thermodynamic modelling very complicated.

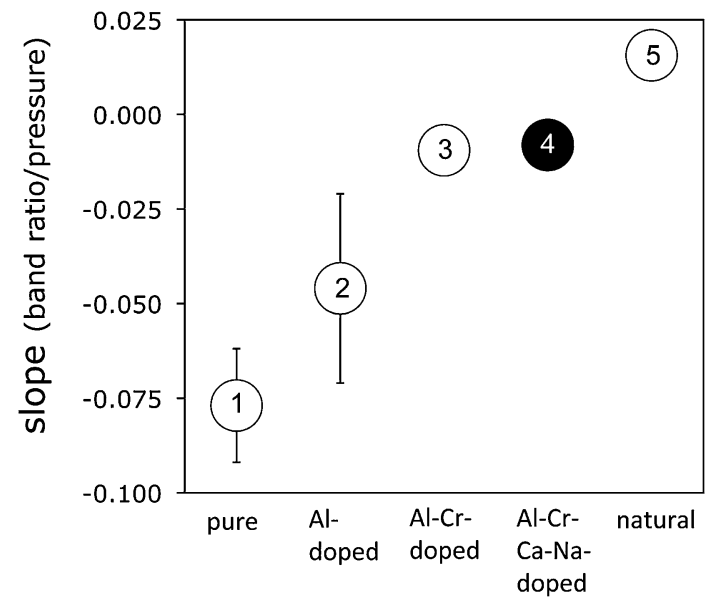

Fig. 9 Evolution of the slope in the band ratio-pressure trend (Fig. 3) with increasing complexity of the chemical system. The large errors for 1 and 2 are due to the large range of band ratios. Data sources: 1 Prechtel and Stalder (2011), 2 Stalder (2004), 3 Prechtel and Stalder (2012), 4 this study, 5 Prechtel and Stalder (2012)

Although the observed trend of IR band ratios for enstatite from the Na-Ca-Al-Cr-doped system does not reproduce the trend observed in natural orthopyroxene from mantle xenoliths, the results of this study are a further step towards closing the gap between pure end member and natural system behaviour (Fig. 9), suggesting that it is justified to apply the band ratio $\left(A_{3240-3570} / A_{3240-3730}\right)$ in natural enstatite as geobarometer.

Acknowledgments Hannes Witting and Fabian Höpperger are thanked for manufacturing the high-pressure assemblies, and Daniela Schmidmair and Martina Tribus are thanked for support with XRD and microprobe analyses, respectively. Jed Mosenfelder and an anonymous reviewer are thanked for constructive reviews. This project was supported by the Austrian Science Fund (FWF): P22367-N21.

Open Access This article is distributed under the terms of the Creative Commons Attribution 4.0 International License (http://creativecommons.org/licenses/by/4.0/), which permits unrestricted use, distribution, and reproduction in any medium, provided you give appropriate credit to the original author(s) and the source, provide a link to the Creative Commons license, and indicate if changes were made.

\section{References}

Bell DR, Rossman GR (1992) Water in the Earth's mantle: the role of nominally anhydrous minerals. Science 255:1391-1397

Bell DR, Ihinger PD, Rossman GR (1995) Quantitative analysis of trace $\mathrm{OH}$ in garnet and pyroxenes. Am Mineral 80:465-474

Bell DR, Rossman GR, Moore RO (2004) Abundance and partitioning of $\mathrm{OH}$ in a high-pressure magmatic system: megacrysts from the monastery kimberlite, South Africa. J Petrol 45:1539-1564

Frey FA, Prinz M (1978) Ultramafic inclusions from San-Carlos, Arizona-petrologic and geochemical data bearing on their petrogenesis. Earth Planet Sci Lett 38:129-176 
Grant K, Ingrin J, Lorand JP, Dumas P (2007) Water partitioning between mantle minerals from peridotite xenoliths. Contrib Mineral Petrol 154:15-34

Hirth G, Kohlstedt DL (1996) Water in the oceanic upper mantle: implications for rheology, melt extraction and the evolution of the lithosphere. Earth Planet Sci Lett 144:93-108

Ingrin J, Skogby H (2000) Hydrogen in nominally anhydrous uppermantle minerals: concentration levels and implications. Eur $\mathbf{J}$ Mineral 12:543-570

Karato S (1990) The role of hydrogen in the electrical conductivity of the upper mantle. Nature 347:272-273

Karimova A, Stalder R (2013) OH in diopside and enstatite at $6 \mathrm{GPa}$ in the system $\mathrm{CaO}-\mathrm{MgO}-\mathrm{SiO}_{2}-\mathrm{H}_{2} \mathrm{O}$. Eur J Mineral 25:299-305

Keppler H, Frost DJ (2005) Introduction to Minerals under extreme conditions. In: Miletich R (ed) EMU notes in mineralogy, vol 7. Eötvös University Press, Budapest, pp 1-30

Lane DL, Ganguly $\mathrm{J}$ (1980) $\mathrm{Al}_{2} \mathrm{O}_{3}$ solubility in orthopyroxene in the system $\mathrm{MgO}-\mathrm{Al}_{2} \mathrm{O}_{3}-\mathrm{SiO}_{2}$ : a reevaluation, and mantle geotherm. J Geophys Res 85B:6963-6972

Libowitzky E, Rossman GR (1997) An IR absorption calibration for water in minerals. Am Mineral 82:1111-1115

Maaløe S, Aoki K-I (1977) The major element composition of the upper mantle estimated from the composition of lherzolites. Contrib Mineral Petrol 63:161-173

Mackwell SJ, Kohlstedt DL, Paterson MS (1985) The role of water in the deformation of olivine single crystals. J Geophsy Res 90:11319-11333

Mei S, Kohlstedt DL (2000) Influence of water on plastic deformation of olivine aggregates 1. Diffusion creep regime. J Geophys Res 105:21457-21469

Mierdel K, Keppler H, Smyth JR, Langenhorst F (2007) Water solubility in aluminous orthopyroxene and the origin of Earth's asthenosphere. Science 315:364-368

Mosenfelder JL, Rossman GR (2013) Analysis of hydrogen and fluorine in pyroxenes: I. Orthopyroxene. Am Mineral 98:1026-1041

Nickel KG, Brey G (1984) Subsolidus orthopyroxene-clinopyroxene systematics in the system $\mathrm{CaO}-\mathrm{MgO}-\mathrm{SiO} 2$ to $60 \mathrm{~kb}$ : a re-evaluation of the regular solution model. Contrib Mineral Petrol $87: 35-42$

Nimis P, Taylor WR (2000) Single clinopyroxene thermobarometry for garnet peridotites. Part I. Calibration and testing of a Cr-inCpx barometer and an enstatite-in-Cpx thermometer. Contrib Mineral Petrol 139:541-554

Oehm J, Schneider A, Wedepohl KH (1983) Upper mantle rocks from basalts of the northern Hessian depression (NW Germany). Tschermaks Min Petr Mitt 32:25-48

Peslier AH, Luhr JF (2006) Hydrogen loss from olivines in mantle xenoliths from Simcoe (USA) and Mexico: mafic alkalic magma ascent rates and water budget of the sub-continental lithosphere. Earth Planet Sci Lett 242:302-319

Peslier AH, Luhr JF, Post J (2002) Low water contents in pyroxenes from spinel-peridotites of the oxidized, sub-arc mantle wedge. Earth Planet Sci Lett 201:69-88
Peslier AH, Woodland AB, Bell DR, Lazarov M, Lapen TJ (2012) Metasomatic control of water contents in the Kaapvaal cratonic mantle. Geochim Cosmochim Acta 97:213-246

Prechtel F, Stalder R (2010) FT-IR spectroscopy with focal plane array detector-a novel tool to monitor the spatial $\mathrm{OH}$-defect distribution in single crystals applied to synthetic enstatite. Am Mineral 95:888-891

Prechtel F, Stalder R (2011) The potential use of OH-defects in enstatite as geobarometer. Contrib Mineral Petrol 162:615-623

Prechtel F, Stalder R (2012) OH-defects in Al- and Cr-doped synthetic enstatites and defect geobarometry on natural orthopyroxenes from the Earth's mantle. Eur J Mineral 24:471-481

Purwin H, Stalder R, Skogby H (2009) Hydrogen incorporation in Feand Na-doped diopsides. Eur J Mineral 21:691-704

Rauch M, Keppler H (2002) Water solubility in orthopyroxene. Contrib Mineral Petrol 143:525-536

Rossman GR (1996) Studies of OH in nominally anhydrous minerals. Phys Chem Miner 23:299-304

Rubie DC, Karato S, Yan H, O’Neill HStC (1993) Low differential stress and controlled chemical environment in multianvil highpressure experiments. Phys Chem Miner 20:315-322

Schlechter E, Stalder R, Behrens H (2012) Electrical conductivity of H-bearing orthopyroxene single-crystals measured with impedance spectroscopy. Phys Chem Miner 39:531-541

Skogby H, Rossman GR (1989) $\mathrm{OH}^{-}$in pyroxene: an experimental study of incorporation mechanisms and stability. Am Mineral 74:1059-1069

Stalder R (2004) Influence of $\mathrm{Fe}, \mathrm{Cr}$ and $\mathrm{Al}$ on hydrogen incorporation in orthopyroxene. Eur J Mineral 16:703-711

Stalder R, Ludwig T (2007) OH incorporation in synthetic diopside. Eur J Mineral 19:373-380

Stalder R, Prechtel F, Ludwig T (2012) No site specific infrared absorption coefficients for $\mathrm{OH}$-defects in pure enstatite. Eur $\mathrm{J}$ Mineral 24:465-470

Sundvall R, Stalder R (2011) Water in upper mantle pyroxene megacrysts and xenocrysts-a survey study. Am Mineral 96:1215-1227

Takahashi E (1986) Melting of a dry peridotites KLB-1 up to 14 $\mathrm{GPa}$-implications on the origin of peridotitic upper mantle. J Geophys Res 91:9367-9382

Wang D, Mookherjee M, Xu Y, Karato S (2006) The effect of water on the electrical conductivity of olivine. Nature 443:977-980

Warren JM, Hauri EH (2014) Pyroxenes as tracer of mantle water variations. J Geophys Res Solid Earth 119:1851-1881

Withers AC, Hirschmann MM (2008) Influence of temperature, composition, silica activity and oxygen fugacity on the $\mathrm{H}_{2} \mathrm{O}$ storage capacity of olivine at $8 \mathrm{GPa}$. Contrib Mineral Petrol 156:595-605 